\title{
Hyaluronan Immobilized Polyurethane as a Blood Contacting Material
}

\author{
Feirong Gong, Yue Lu, Hui Guo, Shujun Cheng, and Yun Gao \\ Key Laboratory for Ultrafine Materials of Ministry of Education, School of Materials Science and Engineering, \\ East China University of Science and Technology, Shanghai 200237, China
}

Correspondence should be addressed to Shujun Cheng, chshj2003@yahoo.cn

Received 1 March 2010; Accepted 16 March 2010

Academic Editor: Shanfeng Wang

Copyright () 2010 Feirong Gong et al. This is an open access article distributed under the Creative Commons Attribution License, which permits unrestricted use, distribution, and reproduction in any medium, provided the original work is properly cited.

\begin{abstract}
Hyaluronan (hyaluronic acid, HA) was immobilized onto the surface of amino-functionalized polyurethane films with the goal of obtaining a novel kind of biomaterial which had the potential in blood-contacting applications. The amino-functionalized polyurethane was prepared by synthesized acidic polyurethane whose pendant carboxyl groups were treated with an excess amount of 1,3-diaminopropane in the presence of N,N-carbonyldiimidazole (CDI). Attenuated total reflection Fourier transform infrared spectroscopy (ATR-FTIR), Raman spectroscopy (RS), scanning electron microscopy (SEM), and water contact angle measurement were used to confirm the surface changes at each step of treatment, both in morphologies and chemical compositions. APTT and PT results showed that HA immobilization could prolong the blood coagulation time, thus HA-immobilized polyurethane (PUHA) exhibited improved blood compatibility. Cytotoxicity analysis showed that the PU-HA films synthesized in this study were cytocompatible and could support human vein endothelial cells (HUVECs) adhesion and proliferation.
\end{abstract}

\section{Introduction}

Thermoplastic polyurethanes (PU) have been widely used for various biomedical applications due to their excellent mechanical properties and proper blood compatibility. Recently, much effort has been focused on polyurethanes as blood-contacting materials, such as cardiovascular biomaterials, hemodialysis blood line sets, central venous catheters (CVC), and IV bags $[1,2]$. However, surface-induced thrombosis, protein fouling, and cytocompatibility have become the major drawbacks that hinder their further biomedical applications as blood-contacting materials. Surface modification is an effective approach to improve the blood compatibility, the size, shape, and mechanical properties of the original material maintained. Many studies have been performed on producing a blood-compatible surface by tailoring with poly(ethylene glycol) (PEG) $[3,4]$, heparin $[5,6]$, heparin-like [7-9], phospholipid polymer [10-13], hirudin [14], sulfobetaine [15, 16], and so on. Although many hydrogels or hydrophilized surfaces exhibit good blood compatibility, most of these are not truly antithrombogenic but only antithromboadhesive [17] as they curtail or inhibit platelets and blood cell adhesion rather than prolong the coagulation time.

Hyaluronan (HA), a linear biopolymer naturally abundant in mammalian tissues, is composed of repeating units of $\mathrm{N}$-acetyl-D-glucosamine and $\mathrm{D}$-glucuronic acid, linked by $\beta-(1,4)$ and $\beta-(1,3)$ glycosidic junctions [18]. HA has been identified as a nontoxic, biodegradable, biocompatible, and nonimmunogenic material, and its degradation products of hyaluronicdase digestion are non-toxic oligomeric sugars that are mitogenic for endothelial cells in vitro and are correlated with blood vessel growth in vitro and in vivo [19-21]. Thus, HA has been widely used in biomedical applications such as scaffolds for wound healing, ophthalmic surgery, arthritis treatment, drug delivery, and implantation [22-25].

In this paper, HA-immobilized polyurethane was synthesized and characterized. The main purpose of this study was to improve the blood compatibility of the PU films by surface immobilization of HA. The coagulation time and the culture of human vein endothelial cells (HUVEC) in vitro were used to evaluate the blood compatibility and cytotoxicity, respectively. 


\section{Materials and Methods}

2.1. Materials. 1, 6-hexane diisocyanate (HDI) was purchased from Bayer with purity greater than $99.5 \%$. Polycarbonate diols (PCDL) with a number average molecular weight of $2000 \mathrm{~g} \cdot \mathrm{mol}^{-1}$ was kindly provided by Asahi Kasei Corporation and dried in vacuum at $50^{\circ} \mathrm{C}$ for 24 hours prior to use. 2,2-bis(hydroxymethyl) propionic acid (bisMPA) was purchased from Acros and used as received. Dimethylformamide (DMF) and tetrahydrofuran (THF) were refluxed over calcium hydride $\left(\mathrm{CaH}_{2}\right)$ for three days and distilled before use. 1,3-diaminepropane and 1-Ethyl3-[3-(dimethylaminopropyl)] carbodiimide hydrochloride $(\mathrm{EDC} \cdot \mathrm{HCl})$, and $\mathrm{N}, \mathrm{N}$-carbonyldiimidazole $(\mathrm{CDI})$ were purchased from GL Biochem Ltd. (Shanghai, China) and used as received. Hyaluronan sodium salt (HA) with different molecular weights $\left(\mathrm{M}_{\mathrm{w}}=10 \times 10^{3}\right.$ and $\left.40 \times 10^{3}\right)$ was purchased from Shanghai Trustin Chemical Co., Ltd (China). Other reagents were commercially available and used as received.

2.2. Preparations of the PU Base Polymer. The acidic polyurethane used in this study was synthesized by the traditional two-step method under nitrogen protection. In an oven-dried four-neck flask equipped with a stir bar, reflux condenser, and nitrogen on command, $0.63 \mathrm{~g}(3.75 \mathrm{mmol})$ of HDI and three drops of dibutyltin dilaurate (DBTDL) were dissolved in $10 \mathrm{~mL}$ of DMF and maintained at $80^{\circ} \mathrm{C}$ with continuous stirring. $5 \mathrm{~g}(2.5 \mathrm{mmol})$ of PCDL dissolved in $20 \mathrm{~mL}$ of DMF was added dropwise to the reactor. The prepolymer synthesis was continued until the isocyanate (NCO) content reached the theoretical value determined by dibutyl amine titration. A $10 \mathrm{~mL}$ solution of chain extender bis-MPA $(0.1675 \mathrm{~g}, 1.25 \mathrm{mmol})$ in DMF was added to the prepolymer solution and was stirred at $80^{\circ} \mathrm{C}$ to allow the chain extending reaction to take place. The mixture was stirred until the NCO peak at $2270 \mathrm{~cm}^{-1}$ in the IR spectrum disappeared. A small amount of methanol was added to the solution to quench the reaction. Subsequently, the polymer solution was poured into a large amount of water and the precipitate was collected after dried in vacuum at $50^{\circ} \mathrm{C}$ for 24 hours. The obtained polymer was then re-dissolved in dichloromethane and the solution was centrifuged at $13,000 \mathrm{rpm}$ for 10 minutes to remove the heavy metal catalyst. Finally, the polymer solution was poured into a large amount of chilled methanol and the precipitate was collected.

2.3. Preparation of Amino-Functionalized Polyurethane (PU$\mathrm{NH}_{2}$ ). PU $(2 \mathrm{~g}, \mathrm{n}[\mathrm{COOH}]=0.5 \mathrm{mmol}$, determined by titration) and CDI $(0.405 \mathrm{~g}, 2.5 \mathrm{mmol})$ were dissolved in $100 \mathrm{~mL}$ of THF and stirred at room temperature for 12 hours to activate the pendant carboxyl groups of the polymer. Then $0.185 \mathrm{~g}$ ( $2.5 \mathrm{mmol})$ of 1,3-diaminepropane dissolved in $10 \mathrm{~mL}$ of THF was added slowly within 0.5 hour. The mixture was allowed to stir at room temperature for additional 12 hours. Once the reaction was completed, the catalyst was filtered off and the solution was centrifuged at 13,000 rpm for 10 minutes, and finally precipitated into excess methanol. This process was repeated again to remove any residue of unreacted CDI. After dried in vacuum at room temperature for 24 hours, $\mathrm{PU}-\mathrm{NH}_{2}$ was obtained as a white solid.

\subsection{Preparation of $\mathrm{PU}-\mathrm{NH}_{2}$ Films and Surface Immobilization} of $\mathrm{HA}$. The PU-NH $\mathrm{N}_{2}$ films were prepared via the solution casting method. A PU- $\mathrm{NH}_{2}$ solution $(10 \%, \mathrm{w} / \mathrm{v})$ was prepared by dissolving the polymer into a glass container having tetrahydrofuran (THF) as solvent. The mixture was stirred continually at room temperature until a homogeneous solution was formed. Then, the solution was poured into leveled $5 \mathrm{~mm}$ PTFE casting plates and cast into films at room temperature for 24 hours. The films were removed from the casting plates and dried in a vacuum oven at $60^{\circ} \mathrm{C}$ for 12 hours to remove residual solvent. Each film was then cut into $2 \mathrm{~cm} \times 2 \mathrm{~cm}$ and the average thickness of the film was about $100 \mu \mathrm{m}$.

Sodium citrate $(22 \mathrm{~g})$ was dissolved in distilled water $(1000 \mathrm{~mL})$ and the $\mathrm{pH}$ of this solution was adjusted to 4.75 by adding $0.1 \mathrm{M} \mathrm{HCl}$ solution. 1-Ethyl-3-[3- (dimethylamidopropyl)] carbodiimide $\cdot$ HCL (EDC.HCL, $10 \mathrm{mg}$ ) was then dissolved in the $\mathrm{pH}$-adjusted solution $(10 \mathrm{~mL})$ to produce a $0.1 \mathrm{wt} \%$ EDC aqueous solution. A certain amount of HA was dissolved in the EDC solution to activate the carboxylic acid groups of HA with gentle stirring. Several pieces of PU-NH $\mathrm{N}_{2}$ films $(2 \mathrm{~cm} \times 2 \mathrm{~cm})$ were immersed into the above solution for surface immobilization of HA. The immobilization reaction was carried out for 12 hours with gentle stirring. The molar ratio of EDC: HA was fixed as $4: 1$. After the immobilization reaction, the films were washed with PBS solutions five times and subsequently rinsed with distilled water in an ultrasonic cleaner for 5 minutes and finally vacuum dried. The $\mathrm{HA}$ immobilized $\mathrm{PU}$ were named as PU-HA ${ }_{1}$ and $\mathrm{PU}-\mathrm{HA}_{4}$, in which the number indicate that the molecular weight of $\mathrm{HA}$ used in the reaction was $10 \times 10^{3}$ and $40 \times 10^{3}$, respectively.

2.5. Spectral Analysis. The ATR-FTIR spectra of the modified PU films were obtained using MAGNA spectrophotometer (Thermo Nicolet, MA, USA) equipped with a ZnSe reflection element. Raman spectra were measured on an inVia+Reflex dispersive Raman spectrometer equipped with a $785 \mathrm{~nm}$ laser. FT-IR measurements were performed on a Nicolet 5700 FTIR spectrophotometer.

2.6. Contact Angle Measurements and Equilibrium Water Content. The water contact angles of the modified and unmodified films were measured using a Ramhart 100 goniometry. For each film, the measurements were repeated in three different areas and at least 10 times for the same area. Finally, the average values were informed.

The equilibrium water content of samples and the effect of ionic strength on the equilibrium swelling ratio were determined according to the methods [26] with slight modification. Three quotients of dried polymer films $(2 \times$ $2 \mathrm{~cm}^{2}$ ) were respectively immersed into phosphate buffered saline (PBS, $\mathrm{pH}=7.4$ ) and distilled water at $37^{\circ} \mathrm{C}$ for 


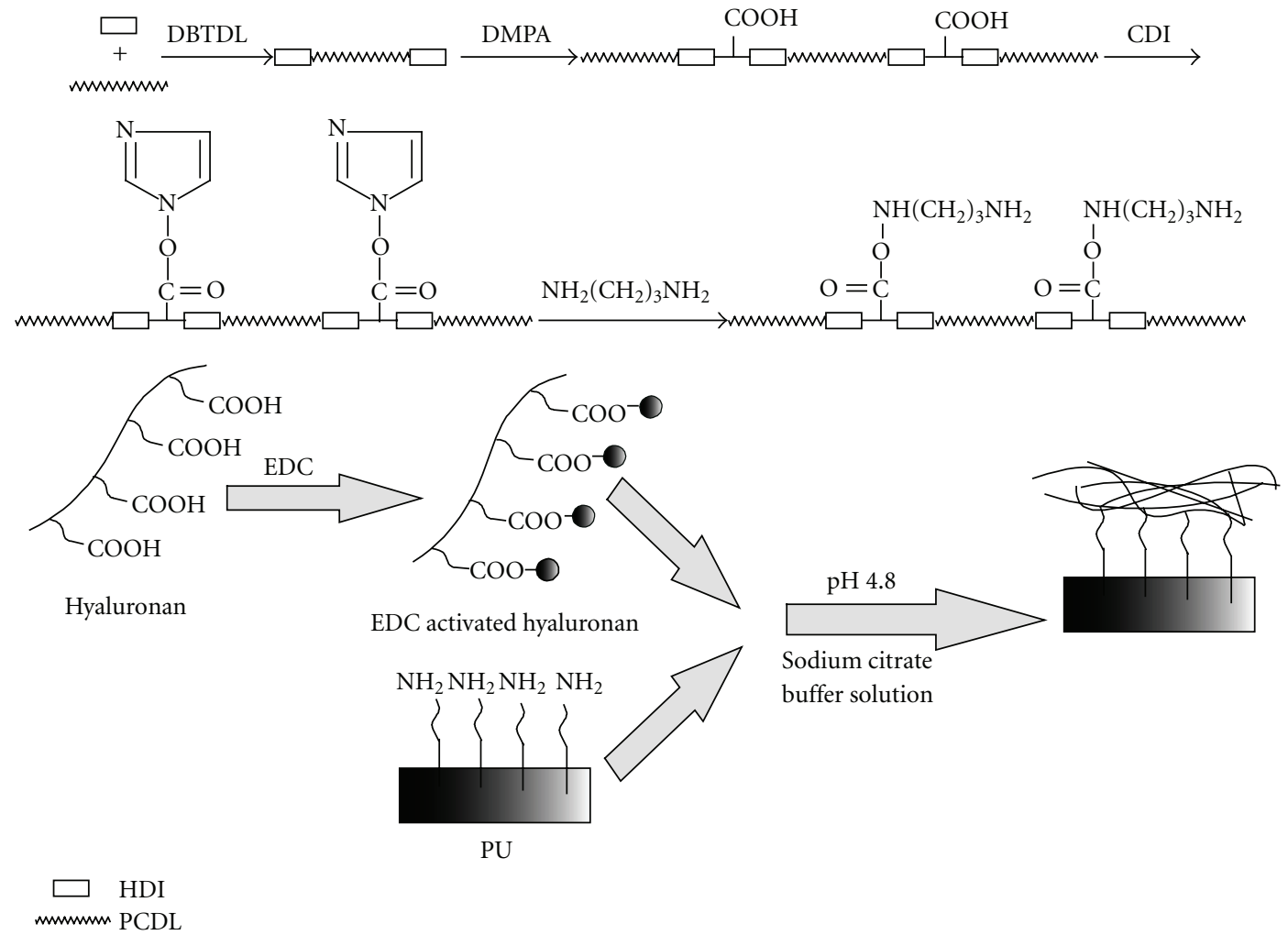

Figure 1: Synthesis of HA-immobilized PU films.

$1,2,4,12,24$, and 48 hours. At each time point, the samples were removed and blotted lightly with filter paper to remove excess water. The weight of the hydrated samples was then determined and the water adsorption was calculated.

\subsection{Scanning Electron Microscope (SEM) Characterization.} The surface morphologies of modified and unmodified surfaces of PU films were characterized by a scanning electron microscope (SEM, JSM-6360LV, JOEL). The samples were coated with a sputtered Au coating in order to prevent charge effects during the observations.

2.8. Coagulation Assays. Coagulation assays were performed to evaluate material-induced abnormalities in the intrinsic and extrinsic coagulation pathways. The end point for these assays was the duration for the onset of fibrin (clot) formation when platelet-poor plasma (PPP) was contacted with the test and control substrates. To obtain PPP, the human whole blood, which was treated with citric acid, was centrifuged at $3000 \mathrm{rpm}$ for 15 minutes to separate the blood corpuscles. Activated partial thromboplastin time (APTT) and prothrombin time (PT) were used in this report.

APTT is a simple and highly reliable measurement of the capacity of blood to coagulate through the intrinsic coagulation mechanism and the effect of the biomaterial on possible delay of the process. The obtained PPP $(0.1 \mathrm{~mL})$, predetermined amounts of test samples and cephalin $(0.1 \mathrm{~mL}$; Actin, Sigma) were placed in a test tube kept at $37^{\circ} \mathrm{C}$, followed by the addition of $0.025 \mathrm{M} \mathrm{CaCl}_{2}$ solution $(0.1 \mathrm{~mL})$ after 5 minutes incubation. The plasma solution was monitored for clotting by manually dipping a stainless-steel wire hook coated with silicon into the solution to detect fibrin threads. Clotting times were recorded at the first signs of any fibrin formation on the hook. The experiment was repeated in quadruplicate and a mean value was calculated. PT was measured to assess HA-induced deferment or interdiction of extrinsic coagulation pathway. Platelet-poor plasma $(0.1 \mathrm{~mL})$ was layered atop the sample at $37^{\circ} \mathrm{C}$, and supplemented with $0.9 \% \mathrm{NaCl}$-thromboplastin (Factor III, $0.1 \mathrm{~mL}$ Sigma) containing $\mathrm{Ca}^{2+}$ was added to the PPP. The clotting time of the plasma solution was observed as described in the APTT experiment. The experiment was repeated in quadruplicate and a mean value was calculated.

2.9. Cell Responses. Cell attachment and proliferation were evaluated by seeding human vein endothelial cells (HUVEC) $\left(1 \times 10^{5}\right.$ cells $\left./ \mathrm{mL}\right)$ on the polymer films in the medium (Dulbecco's modified Eagle's medium, DMEM, Gibco) supplemented with $10 \%$ fetal bovine serum (FBS, Gibco) in 12well tissue culture plates. Next, $3 \mathrm{~mL}$ of medium was added to the wells and mixed with the cells. The cells were then cultured in a humidified incubator equilibrated with 5\% $\mathrm{CO}_{2}-95 \%$ air for 7 days. The cells attached onto the polymer surfaces were observed using a phase contrast microscope. The viability of cells was quantitatively measured by the MTT assay. Their counterparts with incubation with PU were used as a control. 


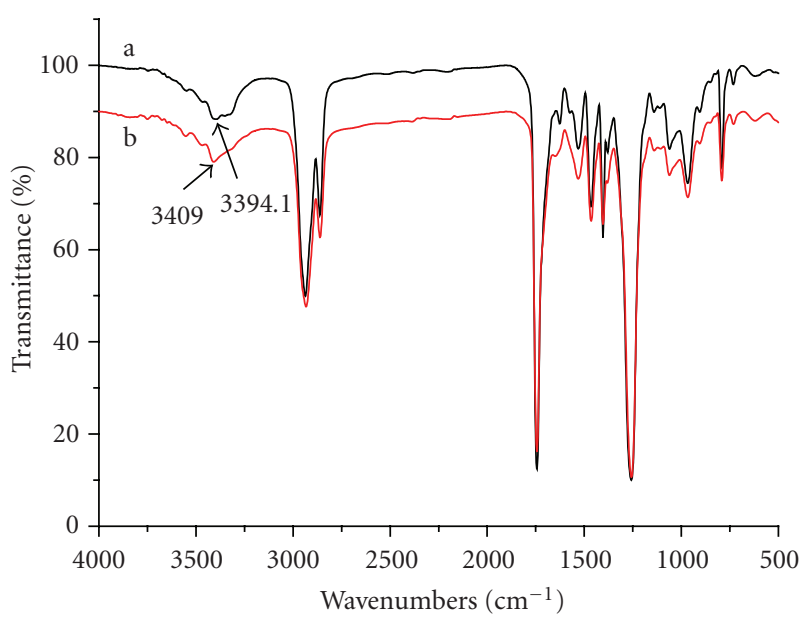

Figure 2: FT-IR spectra of PU (a) and PU-NH $\mathrm{NH}_{2}$ (b).

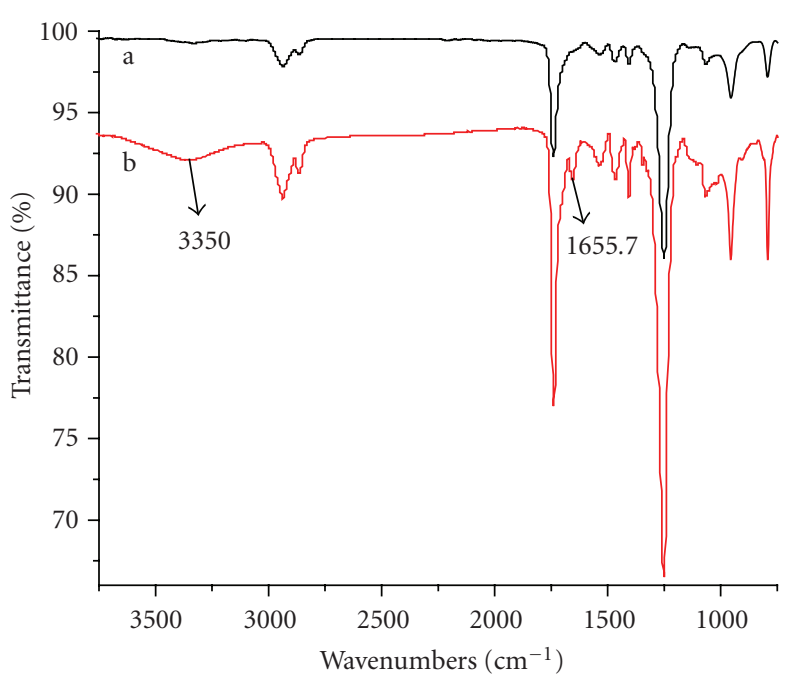

FIgUre 3: ATR-FTIR spectra of PU-NH $\mathrm{NH}_{2}$ (a) and PU-HA films (b).

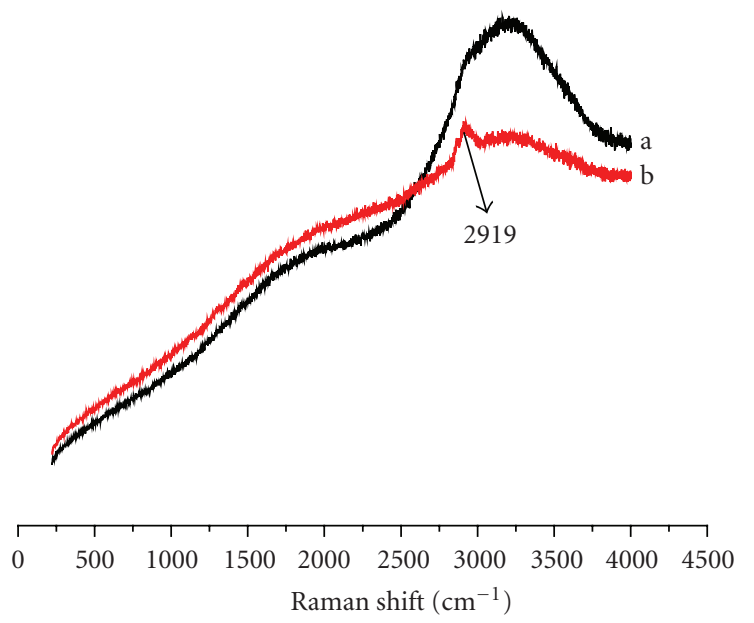

Figure 4: Raman spectra of PU-NH $\mathrm{N}_{2}$ (a) and PU-HA (b).

3.2. Spectral Analysis. To investigate the chemical structure, FT-IR, ATR-FTIR and Raman spectroscopy were performed on PU, PU-NH ${ }_{2}$ and PU-HA. FT-IR spectra of PU (Figure 2) showed characteristic bands of urethane groups at $3394.4 \mathrm{~cm}^{-1}$ (N-H stretching), $1744 \mathrm{~cm}^{-1}$ (NHCOO stretching), and $1531 \mathrm{~cm}^{-1}$ (C-N stretching, combined with $\mathrm{N}-\mathrm{H}$ stretching). All of these peaks provide convincing evidence for the formation of polyurethane. From a preliminary study of FT-IR, it was found that the spectra of PU-NH $\mathrm{N}_{2}$ were almost the same as that of the PU control. This is because the absorption based on the amide $(\mathrm{N}-\mathrm{H})$ of the amino groups in PU-NH $\mathrm{N}_{2}$ was overlapped by the amide bond in PU itself. A slight shift from $3394.4 \mathrm{~cm}^{-1}$ to $3409 \mathrm{~cm}^{-1}$ was observed, which was mainly caused by the formation of amino groups on PU chains. The existence of amino groups on PU films was further confirmed by ninhydrin as the film could display purple when amino reacted with ninhydrin at $80^{\circ} \mathrm{C}$ for 10 minutes. Figure 1. 


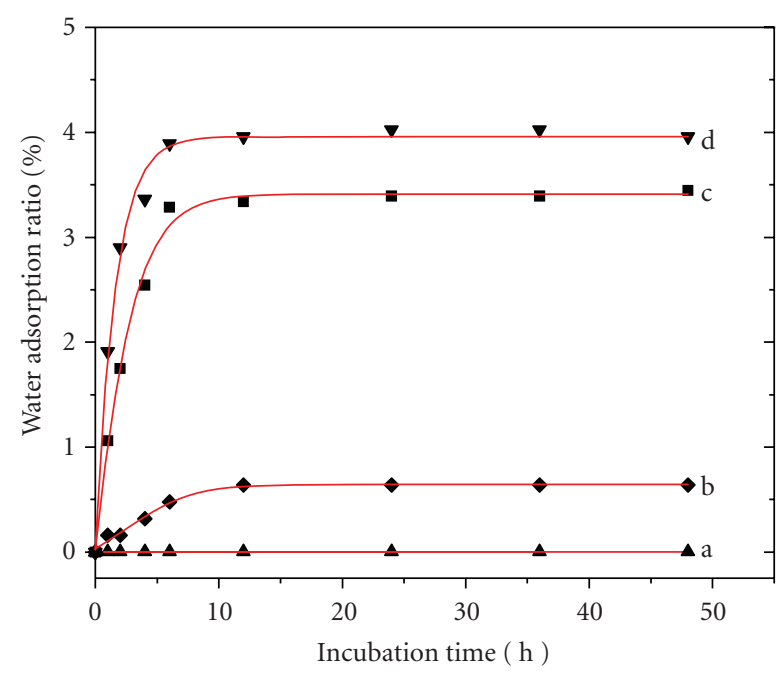

(a)

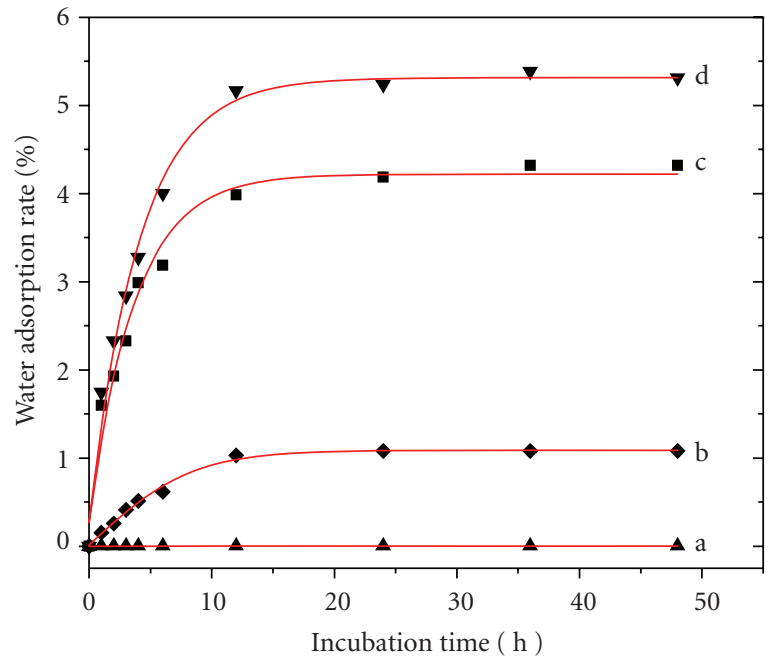

(b)

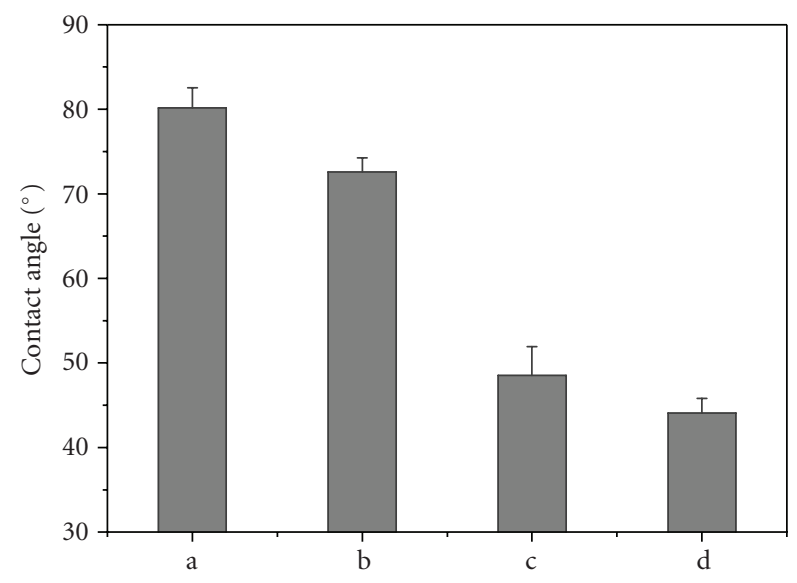

(c)

Figure 5: Water absorption of different PU films; a: PU, b: $\mathrm{PU}-\mathrm{NH}_{2}$, c: $\mathrm{PU}_{-} \mathrm{HA}_{1}, \mathrm{~d}: \mathrm{PU}_{-} \mathrm{HA}_{4}$ in PBS (a), deionized water (b), (c) contact angle results.

Figure 3 shows the ATR-FTIR spectra of PU surfaces immobilized with 1,3-diamine-propane (PU-NH$)$ and $\mathrm{HA}$ (PU-HA). In the spectra of PU-HA, the peaks at $3350 \mathrm{~cm}^{-1}$ and $1657 \mathrm{~cm}^{-1}$ corresponding to the hydroxyl group $(-\mathrm{OH})$ and the amide $\mathrm{C}=\mathrm{O}$ stretching respectively, are related to the presence of HA. Raman spectroscopy (Figure 4) was also used to characterize the surface change before and after HA immobilization. A new peak was observed at $2919 \mathrm{~cm}^{-1}$ which was attributed to the hydroxyl group $(-\mathrm{OH})$ stretching of alcohol chelate since the hydroxyl groups in HA could form a chelated structure.

3.3. Hydrophilicity. The water uptake for the samples in PBS (a) and deionized water (b) at $37^{\circ} \mathrm{C}$ as a function of time was shown in Figure 5. Water uptake was measured to determine the hydrophilicity of PU films before and after modification and this parameter was expected to have an important influence on cell responses. The chemical composition was the main factor controlling the amount of absorbed water. For PU almost no water could be absorbed into the polymer matrix within 48 hours. The hydrophilicity of $\mathrm{PU}-\mathrm{NH}_{2}$ was improved slightly due to the appearance of amino groups. A much more hydrophilic character, which increases as the molecular weight of HA increases, was observed when HA immobilized on the surface. This result was expected, given the highly hydrophilic nature of HA.

The water contact angle measurement of PU, $\mathrm{PU}-\mathrm{NH}_{2}$, and PU-HA was shown in Figure 5(c). The $\mathrm{PU}_{-} \mathrm{NH}_{2}$ film showed a slight decrease in water contact angle of $72^{\circ}$ in contrast to unmodified PU film $\left(80^{\circ}\right)$. This result is consistent with that of water uptake experiment. After immobilizing $\mathrm{HA}$ on $\mathrm{PU}-\mathrm{NH}_{2}$ surface, the water contact angle value further decreased, and decreased slightly with increasing the molecular weight of HA. The decrease of contact angle is an index of the chemical changes occurring on the film surfaces, which renders the surface more hydrophilic with respect to the virgin film. It was expected 


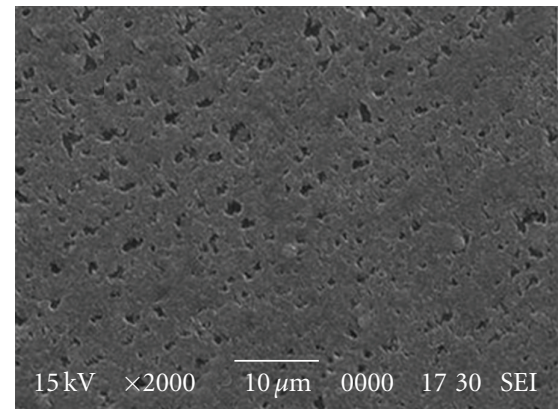

(a)

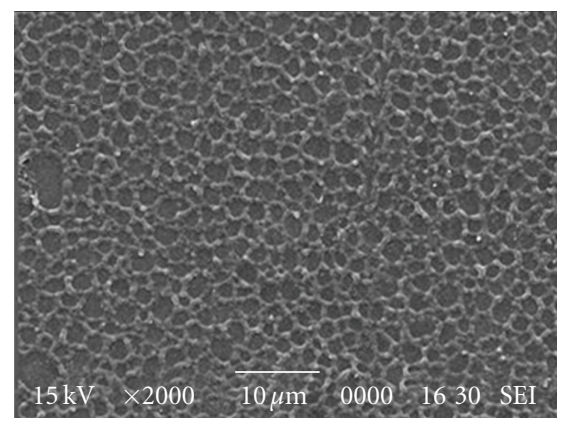

(c)

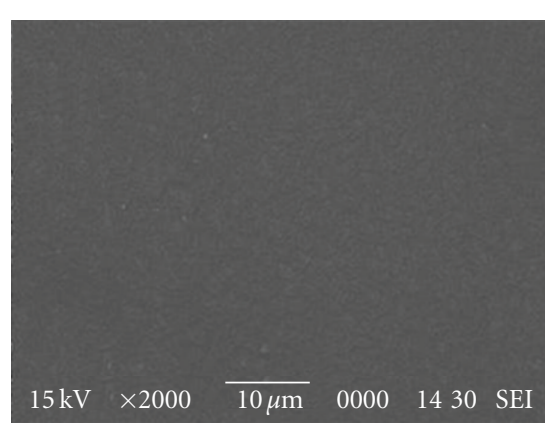

(b)

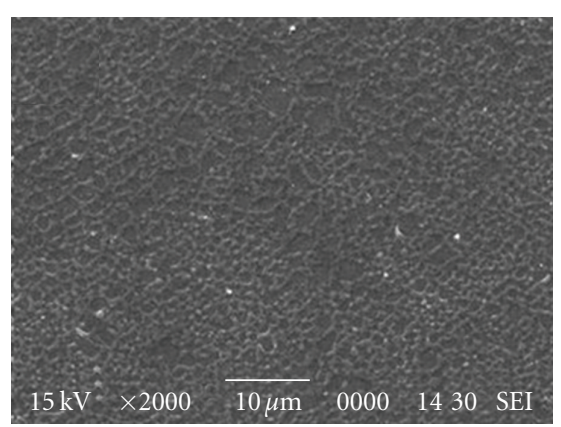

(d)

FIGURE 6: SEM images of the polymer surfaces made at 5000×. (a) PU shows a rough surface. (b) The surface of PU-NH $\mathrm{NH}_{2}$ displays a relatively flat surface. (c) and (d) The surfaces of PU-HA 1 and PU-HA 4 show a semiporous structure.

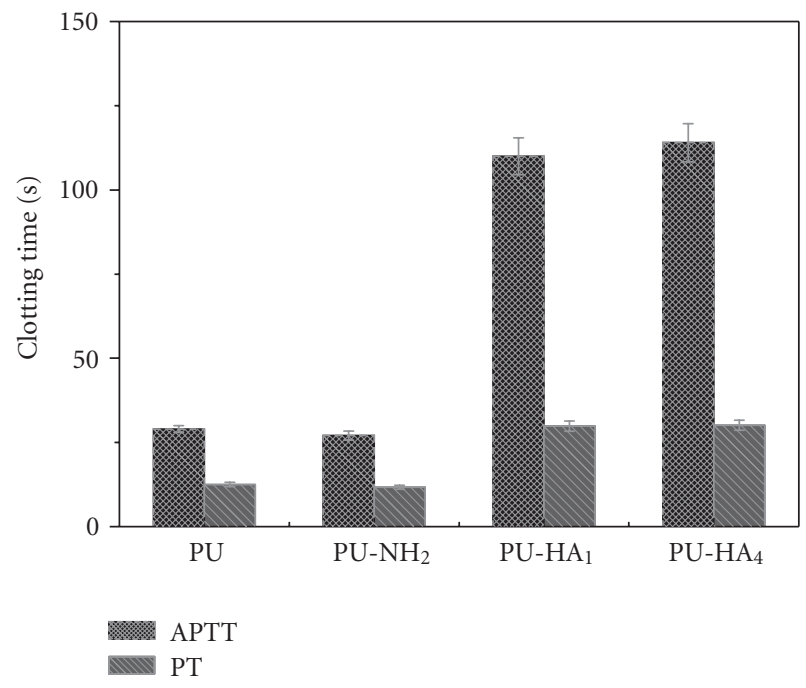

FIGURE 7: Comparison of anticoagulant properties of different films: APTT and PT $(n=3$, mean \pm S.D. $)$.

that the higher hydrophilicity for PU-HA could be induced by a large amount of negatively charged carboxylic groups in HA backbone and rough surface with a large surface area.

3.4. Surface Morphology. SEM micrographs in Figure 6 illustrated the surface morphology changes of PU films before and after each step of treatment. As shown in Figure 6, the surface of PU base polymer was rough with irregular pores. After the first step of 1,3-diaminepropane conjugation, the polymer surface became relatively smooth, which could be interpreted by the improved compatibility of the hard and soft segments after extending the side chain. After the second step of immobilizing $\mathrm{HA}$ on the surface of $\mathrm{PU}-\mathrm{NH}_{2}$ film, a semi-porous structure was observed. The surface morphology certainly affected the related properties of the polymer including wettability, contact angle, and cell responses.

3.5. Coagulation Time. The blood coagulation system includes the intrinsic pathway, the extrinsic pathway, and the common pathway. APTT and PT are used to examine mainly the intrinsic and extrinsic pathway, respectively. Figure 7 shows the clotting time of modified and unmodified PU. PU-NH ${ }_{2}$ shows essentially the same APTT and PT result as the native PU. The APTT and PT for PU, PU-NH and PU-HA were 29s, 12.5s; 27s, 11.7s; 110s, 29.8s; 114s, 30.1s. HA-immobilized PU instead exhibits a strong increase in APTT and PT, thereby exerts an anti-coagulant effect. And the molecular weight of HA has little effect on the blood clotting time. The above results indicate that the anticoagulant activity of the PU films has been retained after HA immobilization. The prolonged APTT and PT of PU-HA films suggested that the coagulation mechanisms probably worked through two pathways: the intrinsic pathway and the extrinsic pathway. 


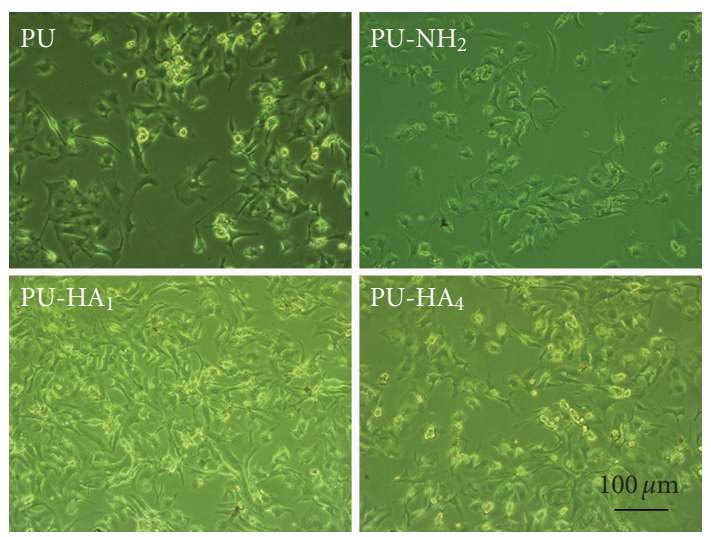

(a)

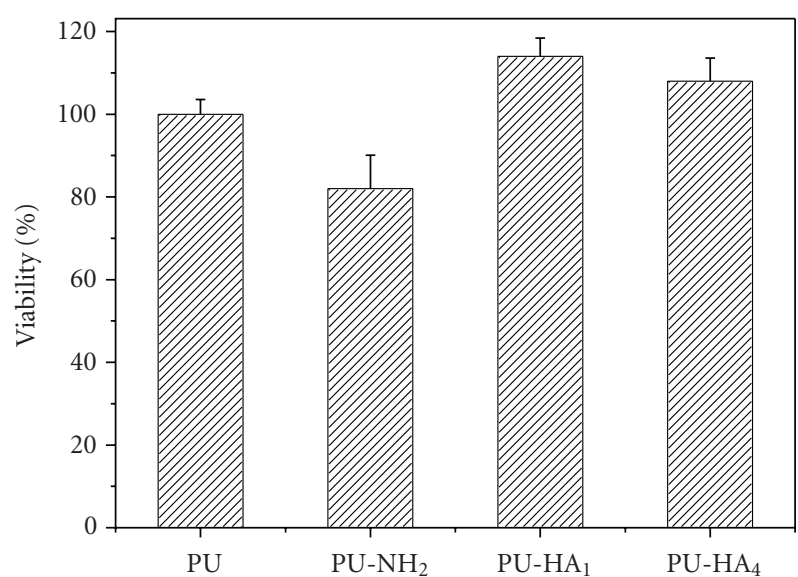

(b)

FIgURE 8: Phase contrast images of HUVECs attached on the surface of PU, $\mathrm{PU}-\mathrm{NH}_{2}, \mathrm{PU}-\mathrm{HA}_{1}$ and $\mathrm{PU}-\mathrm{HA} \mathrm{A}_{4} 7$ days postseeding. There is a significant difference $(P<.05)$ between $\mathrm{PU}$ and $\mathrm{PU}-\mathrm{NH}_{2}, \mathrm{PU}-\mathrm{HA}_{1}, \mathrm{PU}-\mathrm{HA}_{2}$. No significant difference is between PU-HA $\mathrm{P}_{1}$ and PU-HA . The scale bar in the micrograph of PU-HA ${ }_{4}$ stands for $100 \mu \mathrm{m}$ and it is applicable for all micrographs in the panel.

3.6. Cell Attachment. Preliminary studies were performed to evaluate in vitro cell attachment and proliferation on the surfaces of the PU, PU-NH 2 and PU-HA films using HUVECs. Figure 8 shows the morphology of HUVECs adhered to and proliferated on the surface of these polymer films after 7 days post seeding. As shown in Figure 8, there are only a few cells that could adhere to and proliferate on the surface of PU. The number of attached HUVECs decreases while 1,3-diaminepropane was conjugated to $\mathrm{PU}$ probably due to the existence of amino groups which was known to be cytotoxic. In contrast, cells adhere to and proliferate better on PU-HA films. It was also found that the molecular weight of the conjugated HA has some influence on the attachment of the cells. There appeared to be fewer cells adherent on the PU-HA surface with higher molecular weight of HA. The cytotoxicity of the PU films before and after modification was qualitatively investigated by the MTT assay. The result indicated that the viability of cells incubated on the $\mathrm{HA}$ immobilized $\mathrm{PU}-\mathrm{NH}_{2}$ surface was significantly greater than that on the PU and $\mathrm{PU}-\mathrm{NH}_{2}$ $(P<.05)$, suggesting that the HA immobilized PU in this study had a better cytocompatibility. No difference was found between PU-HA 1 and $\mathrm{PU}-\mathrm{HA}_{4}$.

There are many factors influence cell responses on biomaterials: mechanical property [27], electrical surface charge [28], hydrophilicity [29], and surface morphology [30], and so forth. Usually the cell response is a combination of all these different stimuli, so it is impossible to find a unique factor to explain these data. The obtained results can be explained as follows: (a) the difference of the cell number between PU and $\mathrm{PU}-\mathrm{NH}_{2}$ is mainly caused by the electrostatic factor since negatively charged surfaces show increase cells attachment; (b) cells prefer to adhere to PUHA not only because of its rough surface and anionic surface charge, but also because HA is an extracellular matrix (ECM) component; (c) fewer cells adherent to PU-HA 4 with high molecular weight may be influenced by hydrophilicity.

\section{Conclusions}

In this paper, we have synthesized a novel kind of polyurethane with carboxyl groups at the side chain by two-step solution polymerization. In order to provide a convenient way to immobilize HA, free amino groups have been introduced into the PU base polymer. The variation of ATR-FTIR, RS, water contact angle and morphology showed that HA was successfully immobilized on the surface of PU. HA immobilization not only improved the hydrophilicity, but also greatly prolonged the coagulation time and improved the cell biocompatibility in comparison with base PU and PU-NH 2 . Hence, it can be concluded that the HA immobilization is a promising way to enhance cell-material interaction, resulting in a blood-contacting material with high efficiency to accelerate the endothelium regeneration.

\section{Acknowledgments}

This paper was supported by the 863 Project of 2007AA02Z450 from the Ministry of Science and Technology of China. The authors thank Shanghai Aosi Biological Technology Service Co., Ltd. for the help in cell culture and coagulation time test.

\section{References}

[1] Y. Zhu, C. Gao, T. He, and J. Shen, "Endothelium regeneration on luminal surface of polyurethane vascular scaffold modified with diamine and covalently grafted with gelatin," Biomaterials, vol. 25, no. 3, pp. 423-430, 2004.

[2] D.-A. Wang, L.-X. Feng, J. Ji, Y.-H. Sun, X.-X. Zheng, and J. H. Elisseeff, "Novel human endothelial cell-engineered polyurethane biomaterials for cardiovascular biomedical applications," Journal of Biomedical Materials Research A, vol. 65, no. 4, pp. 498-510, 2003. 
[3] H. W. Kim, C. W. Chung, and Y. H. Rhee, "UV-induced graft copolymerization of monoacrylate-poly(ethylene glycol) onto poly(3-hydroxyoctanoate) to reduce protein adsorption and platelet adhesion," International Journal of Biological Macromolecules, vol. 35, no. 1-2, pp. 47-53, 2005.

[4] B. Balakrishnan, D. S. Kumar, Y. Yoshida, and A. Jayakrishnan, "Chemical modification of poly(vinyl chloride) resin using poly(ethylene glycol) to improve blood compatibility," Biomaterials, vol. 26, no. 17, pp. 3495-3502, 2005.

[5] Y. J. Du, J. L. Brash, G. McClung, L. R. Berry, P. Klement, and A. K. C. Chan, "Protein adsorption on polyurethane catheters modified with a novel antithrombin-heparin covalent complex," Journal of Biomedical Materials Research A, vol. 80, no. 1, pp. 216-225, 2007.

[6] Q. Lu, S. Zhang, K. Hu, Q. Feng, C. Cao, and F. Cui, "Cytocompatibility and blood compatibility of multifunctional fibroin/collagen/heparin scaffolds," Biomaterials, vol. 28, no. 14, pp. 2306-2313, 2007.

[7] D. K. Han, N. Y. Lee, K. D. Park, Y. H. Kim, H. I. Cho, and B. G. Min, "Heparin-like anticoagulant activity of sulphonated poly(ethylene oxide) and sulphonated poly(ethylene oxide) grafted polyurethane," Biomaterials, vol. 16, no. 6, pp. 467471, 1995.

[8] F. M. Kanmangne, D. Labarre, H. Serne, and M. Jozefowicz, "Heparin-like activity of insoluble sulphonated polystyrene resins. I. Influence of the surface density, nature and binding of substituted anionic groups," Biomaterials, vol. 6, no. 5, pp. 297-302, 1985.

[9] H. J. Lee, K. D. Park, H. D. Park, et al., "Platelet and bacterial repellence on sulfonated poly(ethylene glycol)-acrylate copolymer surfaces," Colloids and Surfaces B, vol. 18, no. 3-4, pp. 355-370, 2000.

[10] W. Feng, S. Zhu, K. Ishihara, and J. L. Brash, "Adsorption of fibrinogen and lysozyme on silicon grafted with poly(2-methacryloyloxyethyl phosphorylcholine) via surfaceinitiated atom transfer radical polymerization," Langmuir, vol. 21, no. 13, pp. 5980-5987, 2005.

[11] T. Nakaya and Y.-J. Li, "Phospholipid polymers," Progress in Polymer Science, vol. 24, no. 1, pp. 143-181, 1999.

[12] A. Korematsu, Y. Takemoto, T. Nakaya, and H. Inoue, "Synthesis, characterization and platelet adhesion of segmented polyurethanes grafted phospholipid analogous vinyl monomer on surface," Biomaterials, vol. 23, no. 1, pp. 263$271,2002$.

[13] J. Yuan, S. Lin, and J. Shen, "Enhanced blood compatibility of polyurethane functionalized with sulfobetaine," Colloids and Surfaces B, vol. 66, no. 1, pp. 90-95, 2008.

[14] T. Furuzono, K. Ishihara, N. Nakabayashi, and Y. Tamada, "Chemical modification of silk fibroin with 2-methacryloyloxyethyl phosphorylcholine. II. Graftpolymerization onto fabric through 2-methacryloyloxyethyl isocyanate and interaction between fabric and platelets," Biomaterials, vol. 21, no. 4, pp. 327-333, 2000.

[15] J.-C. Lin and S.-M. Tseng, "Surface characterization and platelet adhesion studies on polyethylene surface with hirudin immobilization," Journal of Materials Science: Materials in Medicine, vol. 12, no. 9, pp. 827-832, 2001.

[16] J. Yuan, L. Chen, X. Jiang, J. Shen, and S. Lin, "Chemical graft polymerization of sulfobetaine monomer on polyurethane surface for reduction in platelet adhesion," Colloids and Surfaces B, vol. 39, no. 1-2, pp. 87-94, 2004.

[17] B. D. Ratner, "Blood compatibility-a perspective," Journal of Biomaterials Science, Polymer Edition, vol. 11, no. 11, pp. 11071119, 2000.
[18] K. Surendrakumar, G. P. Martyn, E. C. M. Hodgers, M. Jansen, and J. A. Blair, "Sustained release of insulin from sodium hyaluronate based dry powder formulations after pulmonary delivery to beagle dogs," Journal of Controlled Release, vol. 91, no. 3, pp. 385-394, 2003.

[19] D. C. West, I. N. Hampson, F. Arnold, and S. Kumar, "Angiogenesis induced by degradation products of hyaluronic acid," Science, vol. 228, no. 4705, pp. 1324-1336, 1985.

[20] R. C. Savani, G. Cao, P. M. Pooler, A. Zaman, Z. Zhou, and H. M. DeLisser, "Differential involvement of the hyaluronan(HA) receptors CD44 and receptor for HA-mediated motility in endothelial cell function and angiogenesis," Journal of Biological Chemistry, vol. 276, no. 39, pp. 36770-36778, 2001.

[21] A. Sattar, P. Rooney, S. Kumar, et al., "Application of angiogenic oligosaccharides of hyaluronan increases blood vessel numbers in rat skin," Journal of Investigative Dermatology, vol. 103, no. 4, pp. 576-579, 1994.

[22] S. Y. Lee, J. H. Oh, J. C. Kim, Y. H. Kim, S. H. Kim, and J. W. Choi, "In vivo conjunctival reconstruction using modified PLGA grafts for decreased scar formation and contraction," Biomaterials, vol. 24, no. 27, pp. 5049-5059, 2003.

[23] S. A. Zawko, S. Suri, Q. Truong, and C. E. Schmidt, "Photopatterned anisotropic swelling of dual-crosslinked hyaluronic acid hydrogels," Acta Biomaterialia, vol. 5, no. 1, pp. 14-22, 2009.

[24] H. S. Yoo, E. A. Lee, J. J. Yoon, and T. G. Park, "Hyaluronic acid modified biodegradable scaffolds for cartilage tissue engineering," Biomaterials, vol. 26, no. 14, pp. 1925-1933, 2005.

[25] E. Esposito, E. Menegatti, and R. Cortesi, "Hyaluronan-based microspheres as tools for drug delivery: a comparative study," International Journal of Pharmaceutics, vol. 288, no. 1, pp. 3549, 2005.

[26] T. Segura, B. C. Anderson, P. H. Chung, R. E. Webber, K. R. Shull, and L. D. Shea, "Crosslinked hyaluronic acid hydrogels: a strategy to functionalize and pattern," Biomaterials, vol. 26, no. 4, pp. 359-371, 2005.

[27] C.-M. Lo, H.-B. Wang, M. Dembo, and Y.-L. Wang, "Cell movement is guided by the rigidity of the substrate," Biophysical Journal, vol. 79, no. 1, pp. 144-152, 2000.

[28] M. T. Khorasani, S. MoemenBellah, H. Mirzadeh, and B. Sadatnia, "Effect of surface charge and hydrophobicity of polyurethanes and silicone rubbers on L929 cells response," Colloids and Surfaces B, vol. 51, no. 2, pp. 112-119, 2006.

[29] J. H. Lee, S. J. Lee, G. Khang, and H. B. Lee, "The effect of fluid shear stress on endothelial cell adhesiveness to polymer surfaces with wettability gradient," Journal of Colloid and Interface Science, vol. 230, no. 1, pp. 84-90, 2000.

[30] D.-T. Lin, T.-H. Young, and Y. Fang, "Studies on the effect of surface properties on the biocompatibility of polyurethane membranes," Biomaterials, vol. 22, no. 12, pp. 1521-1529, 2001. 

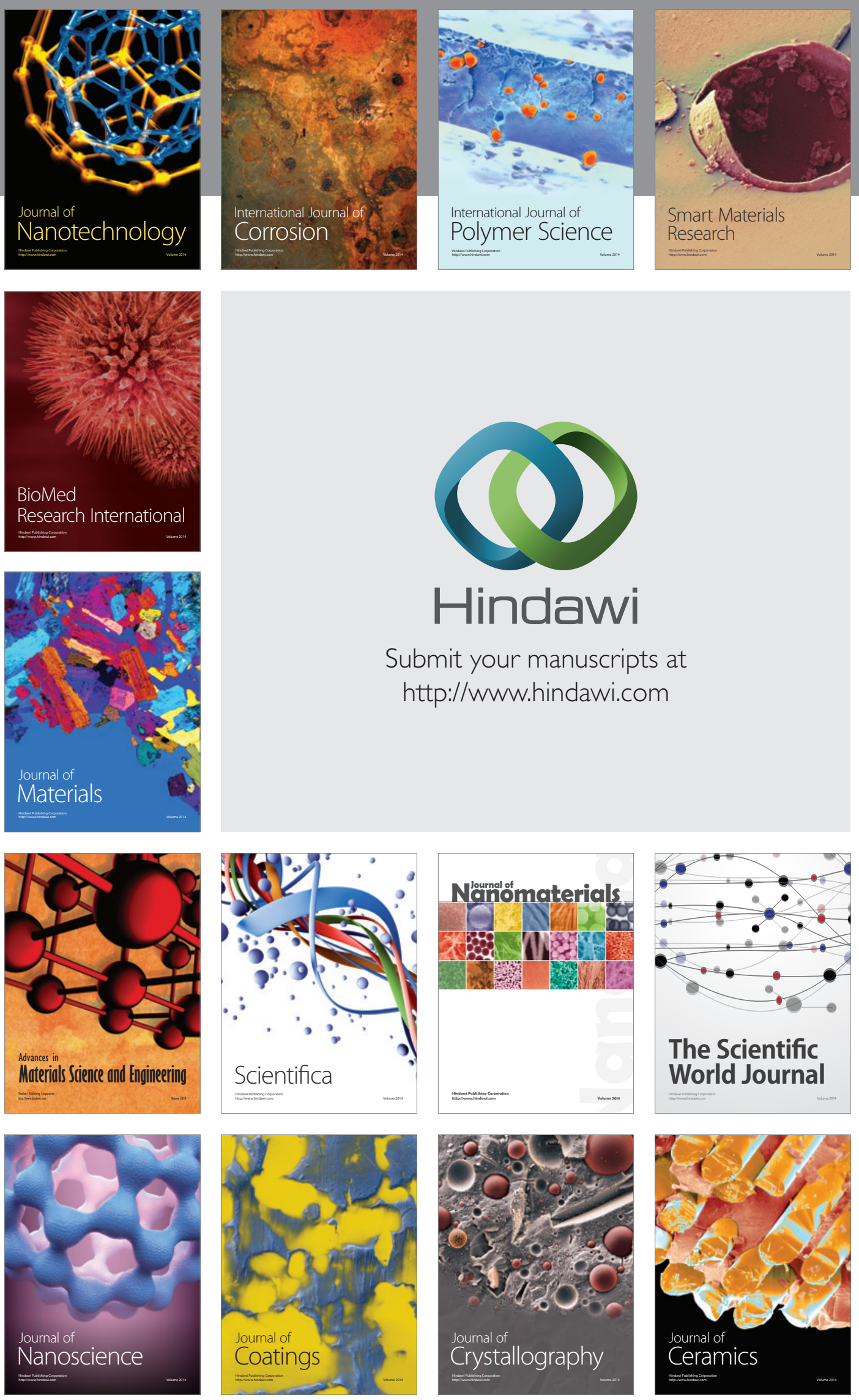

The Scientific World Journal

Submit your manuscripts at

http://www.hindawi.com

\section{World Journal}

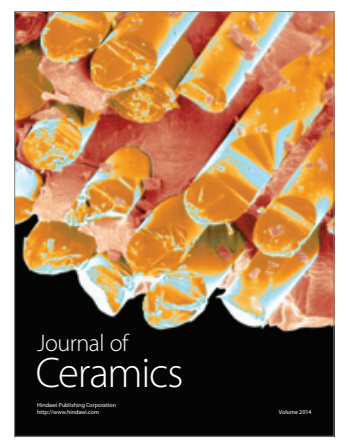

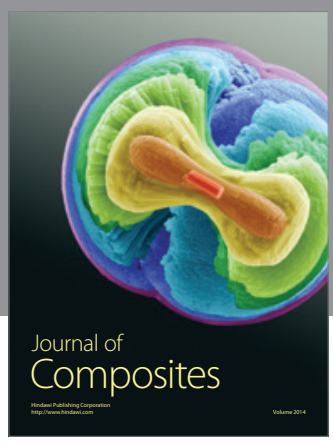
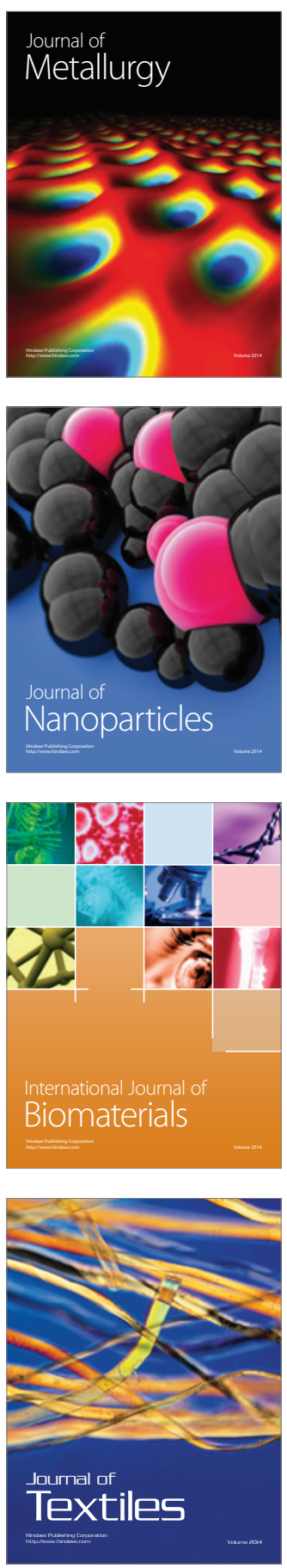